\title{
Microsymposium
}

MS67.004

\section{Control of a thermosalient phase transition by solid solutions}

E. Nauha ${ }^{1}$, M. Lusi ${ }^{1}$, P. Naumov ${ }^{1}$

${ }^{1}$ New York University Abu Dhabi, Center for Science and Engineering, Abu Dhabi, United Arab Emirates

Thermosalient crystals that exhibit macro-scale motion upon phase transition could be useful as actuators that are capable of converting thermal energy into motion or mechanical work in macroscopic devices.[1] The application capability of these miniature actuators for energy conversion depends on the temperature range and dynamics of transition. While the thermo-mechanical performance cannot be systematically varied with a pure molecular crystal, solid solutions could present a way to intentionally tune both the dynamics and the temperature of the transition in a continuous manner (Figure 1). To verify this hypothesis, $\mathrm{Zn}\left(2,2^{\prime}\right.$ bpy) $\mathrm{Br}_{2}$, [2] was selected as a thermosalient material which could form solid solutions (or mixed complexes) with $\mathrm{Zn}\left(2,2^{\prime}-\mathrm{bpy}\right) \mathrm{Cl}_{2}$. Only one form (isomorphous to one of the two $\mathrm{Zn}\left(2,2^{\prime}-\mathrm{bpy}\right) \mathrm{Br}_{2}$ forms) has been reported for the chloride.[3] The results indicate that indeed, the two complexes form solid solutions in varying ratios. The mixed crystals undergo the same phase transformation as the pure $\mathrm{Zn}\left(2,2^{\prime}-\mathrm{bpy}\right) \mathrm{Br}_{2}$ at a $\mathrm{Cl} / \mathrm{Br}$-ratio-dependent temperature. The temperature and dynamics of the thermosalient phenomenon correlates with the $\mathrm{Cl} / \mathrm{Br}$-ratio.

[1] Ž. Skoko, S. Zamir, P. Naumov, J. Bernstein, J. Am. Chem. Soc., 2010, 132, 14191-14202., [2] M. Lusi and J. Bernstein, Chem. Commun., 2013, 49, 9293-9295., [3] M. A. Khan and D. G. Tuck, Acta Cryst., 1984, C40, 60-62.

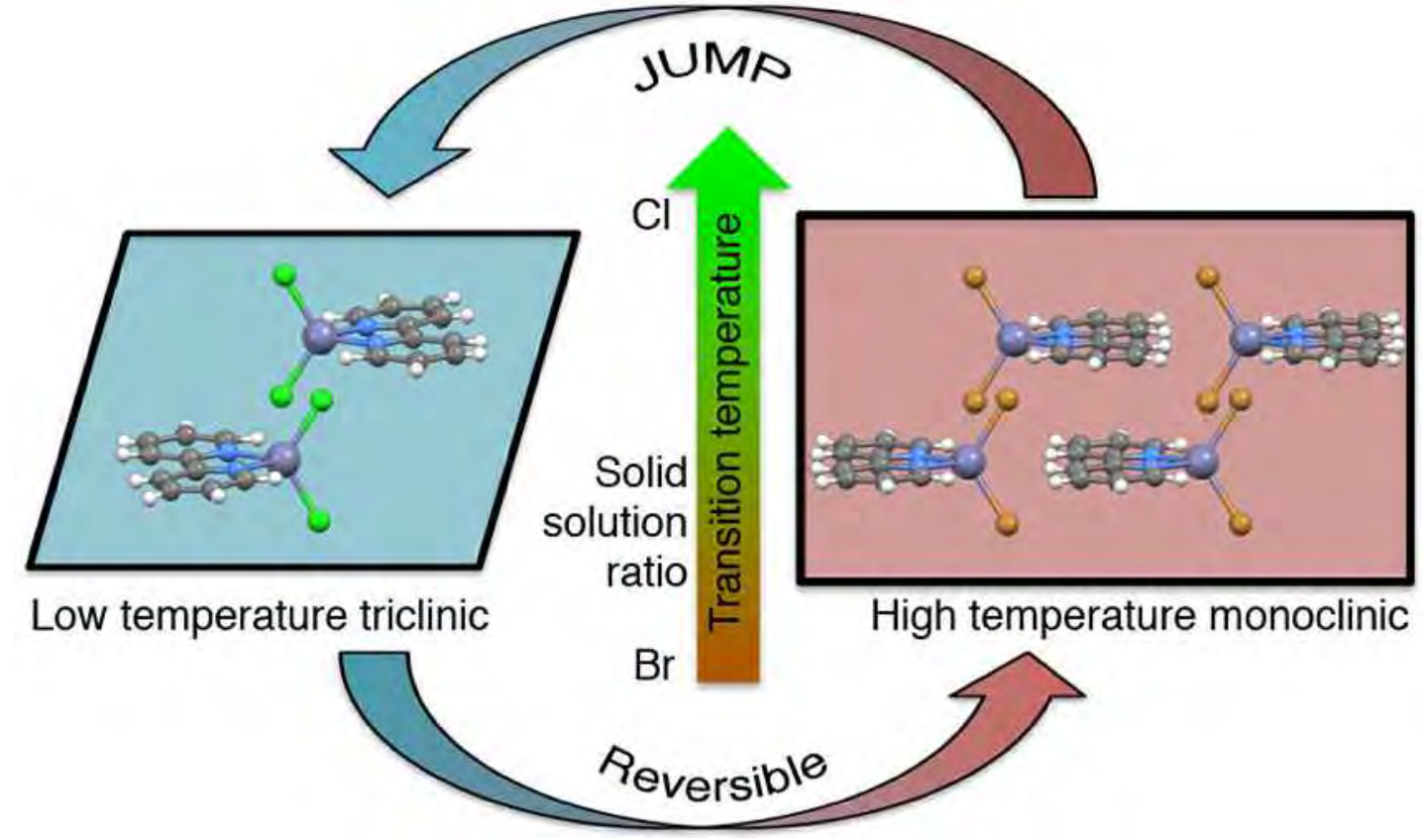

Keywords: thermosalient crystal, solid solution 